\title{
Social marketing potential of qualitative cost- free-to-patient eye care program in a Nigerian community
}

\author{
Abdulkabir Ayansiji Ayanniyi, Sola Bob-Egbe ${ }^{1}$, Fatai Olasunkanmi Olatunji, Charles Oluwole \\ Omolase $^{2}$, Ericson Oluseyi Omolade ${ }^{2}$, Faith Osemiyeme Ojehomon ${ }^{2}$, Michael Kehinde \\ Edward $^{2}$ \\ Department of Ophthalmology, University of Ilorin Teaching Hospital, Ilorin, Nigeria; ${ }^{1}$ General Hospital, Lagos, \\ Nigeria; ${ }^{2}$ Federal Medical Centre, Owo, Nigeria
}

Correspondence to: Dr. Abdulkabir Ayansiji Ayanniyi, Department of Ophthalmology, University of llorin Teaching Hospital, PMB 1459, Ilorin, Nigeria. E-mail: ayanniyikabir@yahoo.com

\begin{abstract}
Background: In 2006, a qualitative, cost-free-to-patient eye care program took place in Owo, Nigeria. This study sought to identify factors that are of marketing importance in qualitative cost-free-to-patient eye care program. Methods: A cross-sectional survey of postoperative patients using interviewer-administered questionnaire to probe into patient socio-demographic factors, source of awareness about the eye care program, initial perception of the program, assessment of the performance of eye care personnel and overall assessment of the eye care program was carried out. Comments of patients on problems encountered and suggestions from them for improvement were noted. Results: Ninety-nine patients comprising of 47 men and 52 women, with age range of 24 to 98 years, participated. Factors of marketing importance identified included publicity through people (46.5\%), town criers (21.2\%), radio $(15.2 \%)$, churches $(8.1 \%)$, mosques $(5.1 \%)$ and banners $(4.0 \%)$. Patients' assessment of the program was as follows: Service to the community (83\%); excellent eye care team performance $(80 \%)$; and overall program rating as follows: Very satisfactory $(76 \%)$, satisfactory $(22 \%)$. The remarkable problem was long waiting period $(15.3 \%)$. Suggestions of the patients were as follows: Improve program sustainability (10.1\%); increase eye care manpower (7.1\%); and public support for the sponsor in order to continue with perceived laudable project 4 (4.0\%).

Conclusion: Adequate publicity, patients' good perception, excellent eye care team performance and patients' overall satisfaction can create awareness about the need to avail of eye care services.
\end{abstract}

Keywords: Community, correct perception, marketing, publicity, qualitative eye care

\section{Résumé}

Arrière-plan: En 2006, une qualitative, coût gratuit au programme de soins oculaires patients déroulé Owo, au Nigéria. Cette étude a cherché à identifier les facteurs qui sont des valeurs marketing la qualitative libre au programme de soins oculaires patient.

Méthodes: Une étude transversale croisée des patients post du dispositif à l'aide d'interviewer administré questionnaire à sonder en patients les facteurs sociodémographiques, source de sensibilisation sur le programme de soins oculaires, perception initiale de la programme, évaluation du rendement de - personnel de soins oculaires et globale évaluation du programme de soins oculaires. Commentaires des patients sur les problèmes rencontré et suggestions d'amélioration a étaient relevées.

Résultats: Quatre-vingt neuf patients comprenant 47 hommes et 52 femmes, avec l'âge de 24 à 98 ans ont participé. Identifie les facteurs de marketing valeur incluse: publicité Grâce à: Personnes (46.5\%), ville crier (21.2\%), radio $(15.2 \%)$, église $(8.1 \%)$, Mosquée $(5.1 \%)$ et la bannière ( $4.0 \%)$. Patients l'évaluation du programme: Le service à la Communauté (83\%), oeil excellents soins équipe performances ( $80 \%$ ), et dans l'ensemble du programme d'évaluation: Très satisfaisant (76\%), satisfaisant (22\%). Le problème remarquable: Long délai d'attente (15.3\%). Suggestions des patients: Programme de développement durable (10.1\%), augmenter les effectifs de soins oculaires (7.1\%) et devez 
aider les donateurs afin de continuer avec projet louable perçue 4 (4.0\%).

Conclusion: Publicité adéquate, bonne perception des patients, soins oculaires excellent équipe performances, et la satisfaction globale des patients peut sensibiliser sur la nécessité de prendre les services de soins oculaires.

Mots clés: Communauté, perception correcte, marketing, publicité, de soins oculaires qualitative

DOI: $10.4103 / 1596-3519.59576$

\section{Page $\mid 226$ Introduction}

Social marketing is a process of generating demand for health care services in the community for those who need health interventions but are not seeking it. Outreach eye camps, mailing and utilizing services of volunteers, among others, are known methods for generating demand for eye care services. ${ }^{[1-3]}$

It is a known fact among eye care providers that people who need eye care the most sometimes do not utilize existing services. ${ }^{[4,5]}$ This has been found to be related to accessibility and affordability of eye care services, ${ }^{[6,7]}$ among other factors, with negative implication for uptake of eye care services, a challenge to Vision 2020: "The Right to Sight". An important strategy for increasing uptake of eye care services is implementing qualitative cost-freeto-patient, accessible eye care programs. ${ }^{[8]}$ The development of "bridging strategies" that create a strong link between hospitals providing clinical service and communities needing these services is a key component to realizing Vision 2020 goals in Sub-Saharan Africa. ${ }^{[9]}$

Many cost-free-to-patient or subsidized eye care services are provided yearly in resource-limited communities across the globe; however, little attention is paid to their marketing potential. Qualitative eye care services are still difficult to access by rural populations, which constitute the majority in resource-limited economy. This is related to many factors: Economic, communication, educational, cultural and scarce resources, among others. ${ }^{[10-14]}$

Qualitative cost-free-to-patient eye care service is expected to attract crowds as quality eye care services are rare in rural communities of resource-limited countries. However, this should never be taken for granted in rural communities of resource-limited countries as communities in such countries have established norms and values. The perception of such a program by the rural communities of resource-limited countries is quite important to its acceptability and utilization. The attitude of the eye care team will mar or make the success of the eye care services. When eye care service is well managed by the provider, it has potential of marketing the eye care service with high returns in terms of awareness creation, positive attitude towards eye health, prevention of blindness, reduced dependency, increased productivity and overall well-being of the nation.

The marketing potential of qualitative, cost-freeto-patient eye care services can be harnessed to raise uptake of eye care services in the community as people will be aware of the available eye care services and will know where to seek treatment. It can be harnessed to attract support from individuals, organizations and governments, as exemplified by international nongovernmental organizations such as Sight Savers International and Orbis Flying Eye Hospital.

Owo, where this study was carried out, is an ancient rural-urban settlement in Ondo state, southwestern Nigeria. Apart from being the headquarters of Owo local government, it has a Federal Medical Centre. As in most other similar settlements in resourcelimited regions, many of the inhabitants are in the low socioeconomic class.

This study sought to ascertain the perspectives of patients about qualitative, cost-free-to-patient eye care programs with the aim of identifying factors that are of marketing importance for qualitative free eye care programs so that eye care providers can pay special attention to such factors and improve uptake of eye care services. To the best of our knowledge, no similar study has been reported from Nigeria.

\section{Materials and Methods}

A qualitative, cost-free-to-patient eye care program took place in Owo, Nigeria, in 2006. Over 3000 patients received medical, optical and surgical treatments. A full complement of eye care practitioners comprising a 50-member eye care team delivered eye care services during the programme. Almost 300 patients had ocular surgeries, including over 200 cataract extractions. The program was in phases: Initial advocacy visits to Owo community/ publicity, eye screening/treatments (optical, medical, counseling and referral), ocular surgery and followup periods. 
This study was carried out during postoperative follow-up visits between the $8^{\text {th }}$ and the $11^{\text {th }}$ of August 2006 at Federal Medical Centre, Owo, Nigeria. A cross-sectional survey of 99 postoperative patients using systematic random sampling technique by interviewing every third patient during postoperative follow-up visits using semi-structured questionnaires previously validated was carried out. Three of the patients refused to give consent and/or were uncooperative on account of postoperative eye discomfort and were replaced by other patients.

Included in the questionnaires were questions related to age, sex and occupation. Other questions were regarding the means of knowing about the cost-free-to-patient eye care program, patient's initial perception of the eye care program, patient's assessment of the performance of eye care team and overall assessment of the cost-free-to-patient eye care program. Comments of patients on problems encountered and suggestions from them for improvement were noted.

The responses were collated, entered into SPSS 12.0.1. and a simple proportion analysis was carried out.

\section{Results}

Ninety-nine patients comprising of 47 (47.5\%) men and 52 (52.5) women whose ages ranged between 24 and 98 years (mean age, 62.6; SD, 15.9) participated. Their occupation included farming (39, 39.4\%), trading $(32,32.3 \%)$, artisans $(8,8.1 \%)$, pensioner $(8,8.1 \%)$, civil service $(5,5.1 \%)$, schooling $(4,4.0 \%)$ and casual work $(3,3.0 \%)$.

The patients knew about the eye care program through other people $(46,46.5 \%)$, town crier $(21,21.2 \%)$, radio announcements $(15,15.2 \%)$, church $(8,8.1 \%)$, mosque $(5,5.1 \%)$ and banners $(4,4.0 \%)$. The patients initially perceived the program as service to the community $(82,82.8 \%)$, being politically motivated $(8,8.1 \%)$ and impossible $(9,9.1 \%)$.

The performance of the eye care team was rated as excellent $(79,79.8 \%)$, good $(14,14.1 \%)$, fair $(4,4.0 \%)$ and poor $(2,2.0 \%)$. The patients' overall assessment of the program was very satisfactory $(76,76.8 \%)$, satisfactory $(22,22.2 \%)$ and unsatisfactory $(1,1.0 \%)$.

The significant problem mentioned by the patients about the program was long waiting period before being seen by eye care specialists $(15,15.3 \%)$. The patients' suggestions included the need to sustain the program $(10,10.1 \%)$, the need to increase the eye care manpower to meet the perceived demands $(7,7.1 \%)$ and the need for the government to assist the donor in order to continue with the perceived laudable project $(4,4.0 \%)$.

\section{Discussion}

Cost-free-to-patient and/or highly subsidized eye care services are conducted often in resourcelimited regions mostly in rural communities. This may not be unrelated to the time-tested fact that those who need eye care the most are poor people residing in rural areas. In addition, most of our resources for eye care services are lopsided in favor of cities; thus rural dwellers have difficulty accessing such services. Rural dwellers have a higher chance of being unaware of eye care services, being exposed to superstitious beliefs and irrelevant cultural values. ${ }^{[15]}$

The commendable act of community assistance by providing qualitative cost-free-to-patient eye care services can create a lasting impression on the community. However, the eye care providers need to pay special attention to a number of factors capable of maximizing the opportunity to benefit eye care services through increased uptake of eye care services. To generate demand for eye care services, it has been shown that outreach programs and patient counseling are powerful marketing techniques. ${ }^{[15]}$

The importance of advocacy by way of reaching out to the community and adequate publicity prior to execution of eye care programs cannot be overemphasized. The community should be in the know of what the program entails, the sponsors, the providers, the beneficiaries, the venue, the duration, the benefits and contacts in case of any enquiry. This will assist the community to have an accurate idea of the program. This study showed that most patients had knowledge of the program through other people. In a communitybased program, people are potent transmitters of information; however, other sources of information such as town crier, radio, religious houses and banners are of benefit, as shown in this study.

Good perception of the program will contribute to making a community-oriented program successful. In this study, most patients perceived the program as service to the community, hence the acceptability and patients' large turnout for the program. Those patients who initially thought the program was being politically motivated could be responding to the prevailing condition in Nigeria, as politicians were campaigning for the 2007 election around the time of the program. Those who thought the program was impossible could be modest as program of this magnitude being privately sponsored was uncommon. The patients' large turnout correlates well with good perception of the program. 
The performance of the eye care team is crucial to the success of an eye care program. This is even more important in a program characterized by large crowds as many would want to be attended to before the end of the program. The eye care personnel even though overworked is expected to function optimally as expected and be courteous to the patients. This will efficiently market eye care services as the patients look up to the eye care providers for solutions to their eye problems. The verdict of excellent performance of the eye care team by most patients is a plus for the program and it has implication for the eye care services in the community. However, the verdict of poor performance of the eye care team by few patients deserves to be investigated and the performance needs to be improved in future outings after giving due consideration to such verdict.

The excellent performance of the eye care personnel most likely resulted in the overall "very satisfactory" verdict of the patients on the program, which was not necessarily due to it being free of cost to the patients.

The long waiting period observed by the patients to see eye care specialists was a significant shortcoming of this program. 'This can be addressed in future programs by a proper estimate of the target population and adequate mobilization of resources. Still, this finding is not peculiar to this study, as $36 \%$ of the respondents reported long waiting time in a study on patients' perception of the quality of eye care in Ibadan. ${ }^{[16]}$

This study is not without its limitations. For instance, the sample size was small; one third of the respondents who had surgery were interviewed. However, the findings are representative of the cohort as the respondents were selected by systematic random sampling technique. Furthermore, the questionnaire being interviewer administered has a likelihood of occurrence of interviewer's error. This is likely to be insignificant as the interviewer had pre-study training and the questionnaire was validated.

\section{Conclusion}

Adequate publicity, patients' good perception, excellent eye care team performance and patients' overall satisfaction can create awareness about the need to avail of eye care services. The ability of the eye care providers to ensure community participation and to provide quality eye care during outreach programs will efficiently market eye care services. Finally, affordable and sustainable eye care services should replace the outreach programs in the community. National Health Insurance should be made operational at the community level so that more people can have access to eye care services.

\section{Acknowledgment}

We are thankful to Ramotu Ibironke Babalakin Trust for organizing the outreach program. The support of the management and staff of Federal Medical Centre, Owo, Nigeria, is hereby acknowledged. Special thanks to the respondents for graciously accepting to participate in this study.

\section{References}

1. Thulasiraj RD, Priya R, Saravanan S. High volume, High Quality Cataract Surgery. Indian Journal of Community Health 1997;3:32.

2. Sil AK. Out reach camps: A case study from West Bengal, India. J Commun Eye Health 2006;19:22-3.

3. Eya'ale D. Beyond the clinic: Approaches to out reach. J Commun Eye Health 2006;19:19-21.

4. Lewallen S, Courtright P. Increasing uptake of eye services by women. J Commun Eye Health 2006;19:59-60.

5. Foster A and Johnson GG. Traditional eye medicine-good or bad news? Br ] Ophthalmol 1994;78:807.

6. Lewallen S, Courtright P. Recognizing and reducing barriers to cataract surgery. ] Comm Eye Health 2000;13:20-1.

7. Adefule-Ositelu AO. Ocular drug abuse in Lagos, Nigeria. Acta Ophthalmol 1989;67:396-4000.

8. The patient's view: How can we improve patient care. J Commun Eye Health 2002;15:3-4.

9. Lewallen $S$, Roberts $H$, Hall $A B$, Onyange $R$, Temba $M$, Banzi ], et al. Increasing cataract surgery to meet Vision 2020 targets: Experience from two rural programmes in east Africa. Br ] Ophthalmol 2005;89:1237-40.

10. Oluleye TS. Cataract blindness and barriers to cataract surgical intervention in three rural communities of Oyo State, Nigeria. Niger ] Med 2004;13:156-60.

11. Rabiu MM. Cataract blindness and barriers to uptake of cataract surgery in a rural community of northern Nigeria. Br j Ophthalmol 2001;85:776-80.

12. Yoston D, Yorston D. High-volume surgery in developing countries. Eye 2005;19:1083-9.

13. Snellingen T, Shrestha BR, Gharti MP, Shrestha JK, Upadhyay MP, Pokhrel RP. Socioeconomic barriers to cataract surgery in Nepal: The South Asian cataract management study. Br ] Ophthalmol 1998;82:1424-8.

14. Osuntokun O. Blindness in Nigeria: The challenge of cataract blindness. The Cataract Backlog. Fourth Faculty of Ophthalmology lecture. National Postgraduate Medical College of Nigeria. Friday August 172001.

15. Sivakumar AK. Professional management for eye care. J Commun Eye Health 2006;19:50-51.

16. Awobem F], Bekibele CO, Bayeroju AM. Patients' perception of the quality of eye care at University College Hospital Ibadan. Niger ] Ophthalmol 2005;13:11-6.

Source of Support: Nil, Conflict of Interest: None declared. 